\title{
SUNCT SYNDROME
}

\section{Report of a possible symptomatic case}

\author{
Guilherme Gustavo Riccioppo Rodrigues, Carlos Alberto Bordini, \\ Fabíola Dach, Alan Eckeli, José Geraldo Speciali
}

\begin{abstract}
SUNCT is one of the rarest and least known primary headache disorders. Although its pathogenesis has been partially understood by functional neuroimaging and reports of secondary cases, there is limited understanding of its cause. We report a case of SUNCT in a 54-years-old man, that could not be strictly classified as secondary SUNCT; however, the time lag of pain onset suggests a new theory in which neuroplasticity could be involved in the origin and duration of the pain in SUNCT syndrome.
\end{abstract}

KEY WORDS: secondary headache, SUNCT syndrome.

\begin{abstract}
Síndrome SUNCT: relato de caso possivelmente sintomático
RESUMO - SUNCT é uma das mais raras e menos conhecidas cefaléias primárias. Embora sua patogênese esteja parcialmente compreendida por neuroimagem funcional e relatos de casos secundários, há insuficiente conhecimento a respeito de sua causa. Nós relatamos um caso de SUNCT em um homem de 54 anos, que não poderia ser estritamente classificado como SUNCT secundário; entretanto, o lapso de tempo para o início da dor sugere uma nova hipótese na qual a neuroplasticidade possa esta envolvida na origem e duração da dor na síndrome SUNCT.
\end{abstract}

PALAVRAS-CHAVE: cefaléia secundária, síndrome SUNCT.

Short-lasting, unilateral, neuralgiform headache with conjunctival injection and tearing (SUNCT) represents one of the rarest primary headache disorders ${ }^{1}$. It has been classified among other short-lasting headache disorders with prominent autonomic features under the general term of trigeminal autonomic cephalalgias (TACS) ${ }^{2}$. SUNCT is characterized by brief, strictly unilateral pain attacks, stabbing or burning in quality, maximal in and around the eye, usually lasting 5-240s, and accompanied by ipsilateral autonomic manifestations. The patients may experience up to 30 attacks per hour, but the frequency is usually 5-6 per hour. The mean age of onset is 51 years old (range 23-77) and there is a male predominance ${ }^{3}$. In the majority of the cases, etiology and pathogenesis are unknown. Accordingly, SUNCT appears in the current classification among the primary headache disorders ${ }^{4}$; (For a recent review see Cohen et al, 2006) $)^{5}$. Studies with functional neuroimaging have been pointing to activation of hypothalamic centers on genesis of autonomic disturbances and pain $^{6-8}$. The response to deep brain stimulation in the hypothalamic area in a patient with intractable SUNCT ${ }^{9}$ renders further support to the hypothesis that this region is the anatomical site of the syndrome. There is evidence that peripheral stimulation of trigeminal afferents could lead to the central disinhibition of hypothalamic centers, forming the trigeminovascular reflex ${ }^{2}$; this may be the explanation for some secondary cases reported in the literature. However, many questions about this headache syndrome remain unanswered.

Herein, besides the report of one possible symptomatic case of SUNCT, we endeavour to explain a feasible pathophysiological mechanism underlying this disorder.

An informed consent was obtained from the patient for publication.

\section{CASE}

A 54 year-old man was first admitted in our emergency unit in March, 1999, with a history of sudden unsteadiness of gait and hypoesthesia in the left side of the face. Except

Department of Neurology, University of São Paulo, School of Medicine at Ribeirão Preto, São Paulo SP, Brazil.

Received 30 January 2007, received in final form 13 April 2007. Accepted 24 May 2007.

Dr. Guilherme G.R. Rodrigues - Ribeirão Preto University Hospital - Avenida Bandeirantes 3900 - 14048-900 Ribeirão Preto SP - Brasil. E-mail: griccioppo@yahoo.com.br 
for hypertension, the patient had no significant past medical history. On physical examination his speech was dysarthric although language was normal. He was oriented to self, place and date. His pupils were equal and reactive to light and fundoscopic examination was normal. Sensation to pin prick and light touch was diminished on the right side of the face and left side of the body. No other alterations of cranial nerves were noticed. His muscle strength and tone were normal. Stretch reflexes were normal and flexor plantar responses were obtained bilaterally. His gait was unsteady with tendency to deviate to the right. Static equilibrium was impaired, falling to the right. Dysmetria was not present on finger-nose testing. MRI was performed demonstrating an infarct of the right dorsolateral medulla (Figure). After three days the patient remained stable and was discharged from hospital with ASA $100 \mathrm{mg}$ a day. In August, 1999 (6 months later), he returned to our service, without neurological deficits, complaining of attacks of an intense right orbital pain, lasting approximately 20 seconds, associated with ipsilateral conjunctival injection and lacrimation, occurring more than 10 times per hour. He has been followed ever since. There was no response to verapamil, sumatriptan tablet, carbamazepine, greater occipital nerve block or lamotrigine.

\section{DISCUSSION}

Several case reports have already been published about symptomatic SUNCT: vascular malformations ${ }^{10,11}$, cavernous haemangioma ${ }^{12}$, dorsolateral

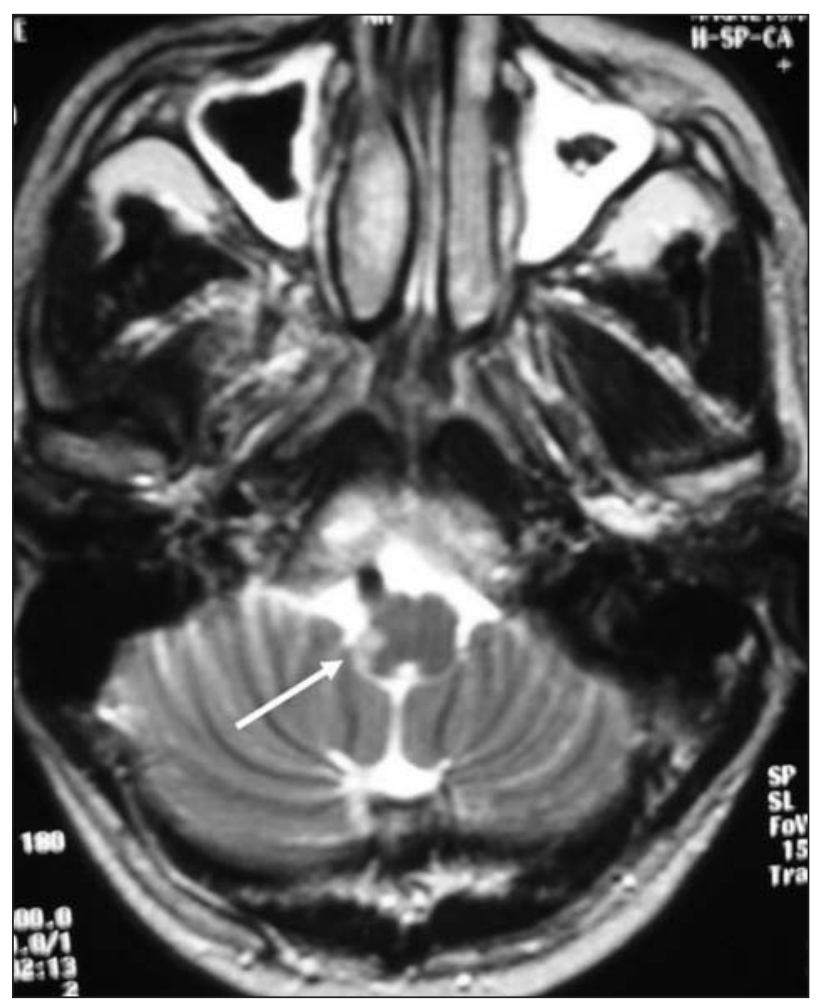

Figure. MRI showing a right dorsolateral medullar infaction (arrow). brainstem infarction ${ }^{13}$, HIV infection ${ }^{14}$, basilar impression secondary to osteogenesis imperfecta ${ }^{15}$, craniosynostosis $^{16}$, leiomyosarcoma of the cavernous sinus ${ }^{17}$, prolactinomas $^{18,19}$, vertebral artery loop ${ }^{20,21}$, pituitary adenomas $^{22,23}$ and chronic maxillary sinus disease ${ }^{24}$ are the underlying reported etiologies.

The present case is striking for the difficulties we face in order to consider it a "symptomatic SUNCT syndrome."

The patient has a definite medullary lesion. As the trigeminal nucleus extends from the midbrain to the second cervical segment, even if the lesion had involved trigeminal areas, a strait forward relationship between the lesion and symptoms might not be established with certainty, because this lesion is not related to the areas demonstrated to be abnormal in SUNCT syndrome according to imaging studies ${ }^{6-8}$.

The headache surged only six months after the stroke, a long period between the lesions and the beginning of the symptoms. A close temporal relationship between the associated disease and the onset of pain was not observed and the putative underlying disorder was not treatable. So, our case does not fulfill IHS criteria for "Secondary Headache Disorder" 4 . Thus, we would suggest that the association herein reported were coincidental.

Similar situations are seen in the literature. In some reports there was not a close temporal relationship between the onset of the pain and the occurrence of the associated disorder ${ }^{10,11,15,16,20-22}$ or remission of the pain after its proper treatment ${ }^{12,17,20,21}$. Some authors seemed to be aware of such discrepancies and, accordingly, admitted that in most of such "secondary" cases were coincidental"25.

On nosological positioning, two possibilities arise: 1) our case is "primary SUNCT" and the previous lesion is simply coincidental; 2) our case is classified under the "Chronic post-vascular disorder headache" (item A6.8 at the appendix of ICHD-II ${ }^{4}$ ). We would be inclined to place our case in this second category as the typical characteristics of these headaches are not known.

However, there is an alternative pathophysiological explanation for this possible symptomatic SUNCT case. Neuronal plasticity has been proposed for the inception of some neurological disturbances like phantom limb phenomena, tinnitus, focal hand dystonia ${ }^{26}$ and even for the beginning and maintenance of pain in diverse clinical situations ${ }^{27-30}$. Besides, new evidences have been presented demonstrating the 
relationship between neuroplasticity and migraine ${ }^{31}$. In a similar way, definite brain damage might induce neuroplastic changes, which in turn would elicit pain. Herein, we propose neuroplasticity as the underlying mechanism for such SUNCT case.

"A close temporal relationship with the underlying cause of the symptoms and resolution with treatment of the associated disorder" is beyond any doubt an important criterion for symptomatic headache disorders; but if one proposes neuroplasticity as the underlying mechanism for such SUNCT case, a new formulation for the above mentioned criterion should be considered. This case could technically be classified under an item like "A6.8", but considering the rarity of the condition, and the relative abundance of those cases ${ }^{10,11,15,16,20-22}$, it is possible that they do not occur as a mere coincidence.

In our opinion our patient could well be classified as "symptomatic SUNCT" instead of chronic post-vascular disorder headache (A6.8). Since it is a beginning hypothesis, for sure, more studies will be necessary, involving a fair number of patients and with the use of more complex methodologies to confirm or refute the neuroplastic hypothesis in the etiology of some cases of SUNCT syndrome.

Acknowledgement - The authors would like to thank Dr. Alan Rapoport for reviewing the English style.

\section{REFERENCES}

1. Sjaastad O, Saunte C, Salvesen R, et al. Short lasting unilateral neuralgiform headache attacks with conjunctival injection, tearing, sweating, and rhinorrhea. Cephalalgia 1989; 21:147-156.

2. Goadsby PJ, Lipton RB. A review of paroxysmal hemicranias, SUNCT syndrome and other short lasting headaches with autonomic feature, including new cases. Brain 1997;21:193-209.

3. Pareja JA, Sjaastad O. SUNCT syndrome. A clinical review. Headache 1997; 37:195-202.

4. Headache Classification Subcommittee of the International Headache Society. The International Classification of Headache Disorders, 2.Ed. Cephalalgia 2004;24(Suppl 1):S1-S160.

5. Cohen AS, Matharu MS, Goadsby PJ. Short-lasting unilateral neuralgiform headache attacks with conjunctival injection and tearing(SUNCT) or cranial autonomic features(SUNA): a prospective clinical study of SUNCT and SUNA. Brain 2006;129:2746-2760

6. May A, Bahra A, Buchel C, Turner R, Goadsby PJ. Functional magnetic resonance imaging in spontaneous attacks of SUNCT: short-lasting neuralgiform headache with conjunctival injection and tearing. Ann Neurol 1999;46:791-794.

7. Leone M, May A, Franzini A, et al. Deep brain stimulation for intractable chronic cluster headache: proposals for patient selection. Cephalalgia 2004;24:934-937.

8. Schoenen J, Di Clemente L, Vandenheede M, et al. Hypothalamic stim- ulation in chronic cluster headache: a pilot study of efficacy and mode of action. Brain 2005:128;940-947.

9. Leone M, Franzini A, D’Andrea G, Broggi G, Casucci G, Bussone G. Deep brain stimulation to relieve drug-resistant SUNCT. Ann Neurol 2005;57:924-927.

10. Bussone G, Leone M, Dalla Volta G, Strada L, Gasparotti R, Di Monda V. Short lasting unilateral neuralgiform headache attacks with tearing and conjunctival injection: the first 'symptomatic' case? Cephalalgia $1991 ; 21: 123-127$.

11. Morales F, Mostacero E, Marta J, Sanchez S. Vascular malformation of the cerebellopontine angle associated with 'SUNCT' syndrome. Cephalalgia 1994;14:301-302.

12. De Benedittis G. SUNCT syndrome associated with cavernous angioma of the brain stem. Cephalalgia 1996;16:503-506.

13. Penart A, Firth M, Bowen JRC. Short-lasting unilateral neuralgiform headache with conjunctival injection and tearing (SUNCT) following presumed dorsolateral brainstem infarction. Cephalalgia 2001; 21:236-239.

14. Barea LM, Forcelini CM. Onset of short-lasting, unilateral, neuralgiform headache with conjunctival injection and tearing (SUNCT) after acquiring human immunodeficiency virus (HIV): more than a coincidence? Cephalalgia 2001;21:518.

15. ter Bergh JWM, Goadsby PJ. Significance of atypical presentation of symptomatic SUNCT. a case report. J Neurol Neurosurg Psychiatry 2001;70:244-246.

16. Morís G, Ribacoba R, Solar DN, Vidal JA. SUNCT syndrome and seborrheic dermatitis associated with craneosynostosis.Cephalalgia 2001; 21:157-159.

17. Kaphan E, Eusebio A, Donnet A, Witjas A, Chérif AA. Shortlasting, unilateral, neuralgiform headache attacks with conjunctival injection and tearing (SUNCT syndrome) and tumor of the cavernous sinus. Cephalalgia 2003; 23: 395-399

18. Massiou H, Launay JM, Levy C, El Amarani M, Emperauger B, Bousser MG. SUNCT syndrome in two patients with prolactinomas and bromocriptine-induced attacks. Neurology 2002; 58:1698-1699.

19. Matharu MS, Levy MJ, Merry RT, Goadsby PJ. SUNCT syndrome secondary to prolactinoma. J Neurol Neurosurg Psychiatry 2003;74:15901592.

20. Zidverc-Trajkovic J, Mijajlovic M, Pavlovic AM, Jovanovic Z, Sternic N. Vertebral artery vascular loop in SUNCT and concomitant trigeminal neuralgia: case report. Cephalalgia 2005;25:554-557.

21. Mondéjar B, Cano EF, Pérez I, et al. Secondary SUNCT syndrome to a variant of the vertebrobasilar vascular development. Cephalalgia 2006;26:620-622.

22. PAS Rocha Filho, Galvão ACR, Teixeira MJ, et al. Sunct syndrome associated with pituitary tumor. Arq Neuropsiquiatr 2006;64:507-510.

23. Rozen TD. Resolution of SUNCT after removal of a pituitary adenoma in mild acromegaly. Neurology 2006;67:724.

24. Bichuetti DB, Yamaoka WY, Bastos JRP, Carvalho DS. Bilateral sunct syndrome associated to chronic maxillary sinus disease. Arq Neuropsiquiatr 2006;64:504-506.

25. Trucco M, Mainardi F, Maggioni F, Badino R, Zanchin G. Chronic paroxysmal hemicrania, hemicrania continua and SUNCT syndrome in association with other pathologies: a review. Cephalalgia 2004;24:173-184.

26. Elbert T, Rockstroh B. Reorganization of human cerebral cortex: the range of changes following use and injury. Neuroscientist 2004;10:129-141.

27. Mackenzie J. Some points bearing on the association of sensory disorders and visceral diseases. Brain 1893;16:321-354.

28. Katz J, Melzack R. Pain "memories" in phantom limbs: review and clinical observations. Pain 1990;43:319-336.

29. Woolf CJ, Salter MW. Neuronal plasticity: increasing the gain in pain. Science 2000;288:1765-1769.

30. Petersen-Felix S, Curatolo M. Neuroplasticity: an important factor in acute and chronic pain. Swiss Med Wkly 2002;132:273-278.

31. Maneyapanda SB, Venkatasubramanian A. Relationship between significant perinatal events and migraine severity. Pediatrics 2005;116: 555-558. 